\title{
NMR assignment of the N-terminal region of human La free and in complex with RNA
}

\author{
Domenico Sanfelice • Geoff Kelly • Stephen Curry • \\ Maria R. Conte
}

Received: 16 April 2008/Accepted: 14 May 2008/Published online: 5 June 2008

(C) The Author(s) 2008

\begin{abstract}
H},{ }^{15} \mathrm{~N}$ and ${ }^{13} \mathrm{C}$ chemical shift assignments are presented for the $\mathrm{N}$-terminal region of human La protein, in the apo and 5'-UUUU RNA-bound state. Secondary structure analysis shows conformational changes in the interdomain linker upon complex formation.
\end{abstract}

Keywords La autoantigen - NMR resonance assignment . RNA interaction

\section{Biological context}

The N-terminal domain (NTD) of the human La protein, containing a La motif and an RNA Recognition Motif (RRM), is responsible for stable and specific interaction with RNA targets terminating in $3^{\prime}-\mathrm{UU}_{\mathrm{OH}}$. This includes pretRNAs and other RNA polymerase III transcripts, for which folding, processing and maturation are assisted by the La protein (Wolin and Cedervall 2002). Other RNA targets that lack terminal or internal poly(U) sequences, such as viral and cellular mRNAs, have also been reported to interact with the La protein, but the mechanism of recognition remains unclear (Wolin and Cedervall 2002). Structural studies by

D. Sanfelice $\cdot$ M. R. Conte $(\square)$

Randall Division of Cell and Molecular Biophysics,

King's College London, New Hunt's House, Guy's Campus, London SE1 1UL, UK

e-mail: sasi.conte@kcl.ac.uk

G. Kelly

Biomedical NMR Centre, National Institute for Medical

Research, Mill Hill, London NW7 1AA, UK

S. Curry

Biophysics Section, Blackett Laboratory, Imperial College,

Exhibition Road, London SW7 2AZ, UK
NMR and X-ray revealed that the $3^{\prime}$-poly(U) recognition by La NTD is synergistically mediated by the La domain, an atypical member of the winged helix-turn-helix family, and the RRM; furthermore, this interaction involves structural motifs which are not the canonical nucleic acid binding surfaces in both classes of proteins, highlighting a novel mode of interaction with RNA ligands (Alfano et al. 2004; Curry and Conte 2006; Teplova et al. 2006).

Using a combination of NMR and X-ray techniques we have recently shown that in the apo La NTD the two domains tumble independently in solution, with the interdomain linker mostly unstructured (Kotik-Kogan et al. 2008). Upon RNA binding however this region becomes $\alpha$-helical and the two domains adopt a rigid conformation with respect to each other. The RNA interaction is mostly dominated by the last two uridines, but preceding Us are also involved in base-specific contacts. Notably, at least two alternative conformations of the 3 '-ends of bound ssRNA could be observed, underscoring a conformational plasticity in the allowable modes of RNA binding by the La protein (Kotik-Kogan et al. 2008).

RNA binding studies in solution have been carried out titrating several ssRNA ligands into a solution of La NTD and observing the chemical shift changes of the protein resonances. Furthermore NMR analysis of NOE patterns, chemical shift and backbone dynamics were essential to further our understanding of how La recognises the $3^{\prime}$-end of RNA targets. Here we report the assignment of ${ }^{1} \mathrm{H},{ }^{15} \mathrm{~N}$ and ${ }^{13} \mathrm{C}$ resonances of La NTD (1-194) in the apo conformation and bound to $5^{\prime}$-UUUU.

\section{Methods and experiments}

Expression and purification protocols of La NTD, encompassing residues 1-194, were carried out as reported 
previously (Alfano et al. 2004). NMR samples contained $0.2-0.4 \mathrm{mM}$ of doubly labelled apo protein in $20 \mathrm{mM}$ Tris$\mathrm{HCl}, 100 \mathrm{mM} \mathrm{KCl}, 1 \mathrm{mM}$ DTT, $10 \% \mathrm{D}_{2} \mathrm{O}, \mathrm{pH}$ 7. The sample of La NTD/5'-UUUU complex was prepared by adding 1.2 eq. of unlabelled RNA to a solution of doubly labelled protein in $20 \mathrm{mM}$ Tris- $\mathrm{HCl}, 100 \mathrm{mM} \mathrm{KCl}, 1 \mathrm{mM}$ DTT, $10 \% \mathrm{D}_{2} \mathrm{O}, \mathrm{pH}$ 7. The final concentration of the 1:1 protein:RNA complex was around $0.3-0.5 \mathrm{mM}$.

NMR spectra were recorded at $293 \mathrm{~K}$ on Varian Inova spectrometers operating at 14.1 and $18.8 \mathrm{~T}$ and Bruker Avance spectrometers operating at 14.1 and $16.4 \mathrm{~T}$, processed using NMRPipe/NMRDraw (Delaglio et al. 1995) and analysed using XEASY (Bartels et al. 1995) and NMRView (Johnson and Blevins 1994).

The ${ }^{1} \mathrm{H},{ }^{15} \mathrm{~N}$ and ${ }^{13} \mathrm{C}$ resonance assignment was obtained for La NTD in the apo and $5^{\prime}$-UUUU-bound states. The standard suite of heteronuclear triple resonance 3D spectra (HNCA, HNCOCA, HNCACB, CBCACONH and HNCO) was used to establish correlations among backbone resonances. The side chain assignments were obtained from 3D HCCH-TOCSY, ${ }^{13} \mathrm{C}$-edited NOESY and ${ }^{15} \mathrm{~N}$-edited NOESY. Samples of both apo and bound protein degraded relatively rapidly after 3-4 days at $293 \mathrm{~K}$, therefore a number of samples had to be prepared to complete the set of NMR experiments needed.

\section{Assignments and data deposition}

The ${ }^{1} \mathrm{H}_{-}{ }^{15} \mathrm{~N}$ HSQC spectra of La NTD free and RNA-bound are shown in Fig. 1. Numerous chemical shifts changes were observed upon complex formation (Fig. 2).

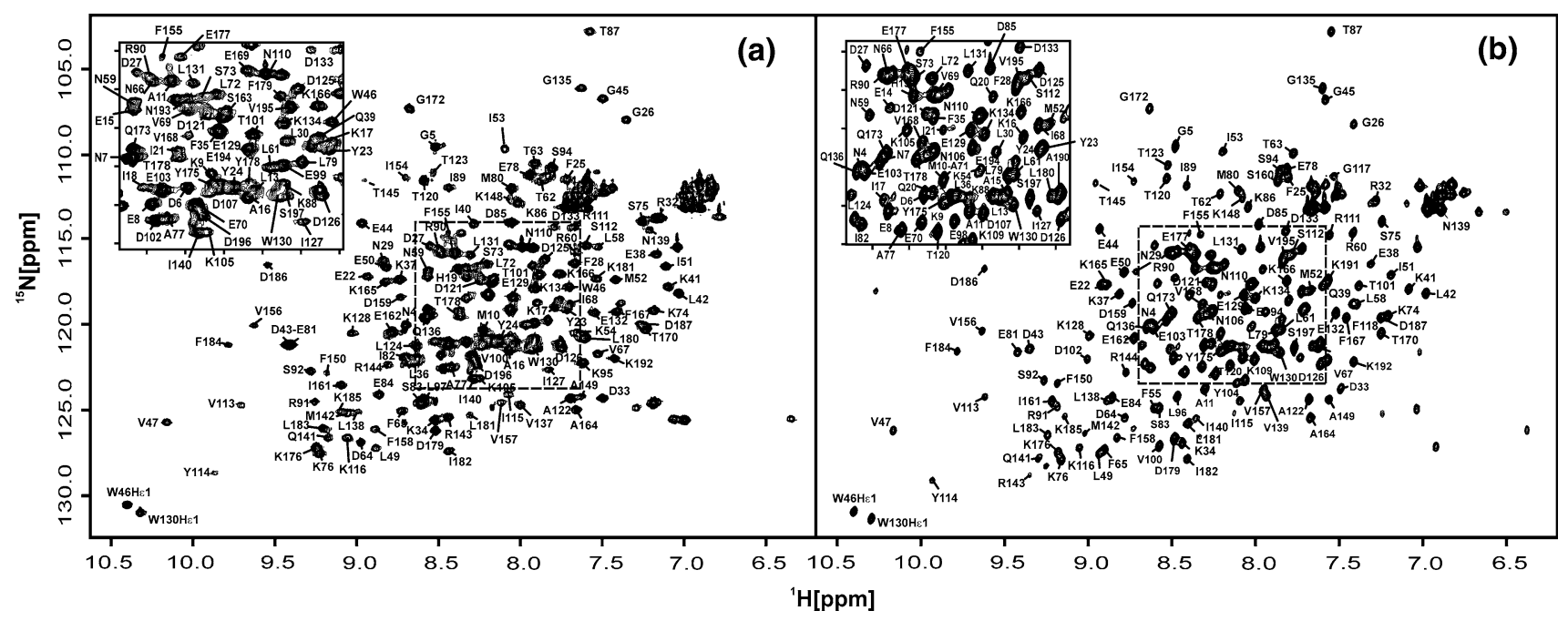

Fig. $1{ }^{1} \mathrm{H}-{ }^{15} \mathrm{~N}$ HSQC spectra of La NTD. (a) Apo protein in $20 \mathrm{mM}$ Tris- $\mathrm{HCl}, 100 \mathrm{mM} \mathrm{KCl}, 1 \mathrm{mM}$ DTT, $10 \% \mathrm{D}_{2} \mathrm{O}, \mathrm{pH}$ 7; (b) 5'-UUUU RNA-bound protein in the same buffer. Resonances are labelled with

the corresponding sequence positions. Inserts show a magnified view of the central part of the spectra (in boxes)

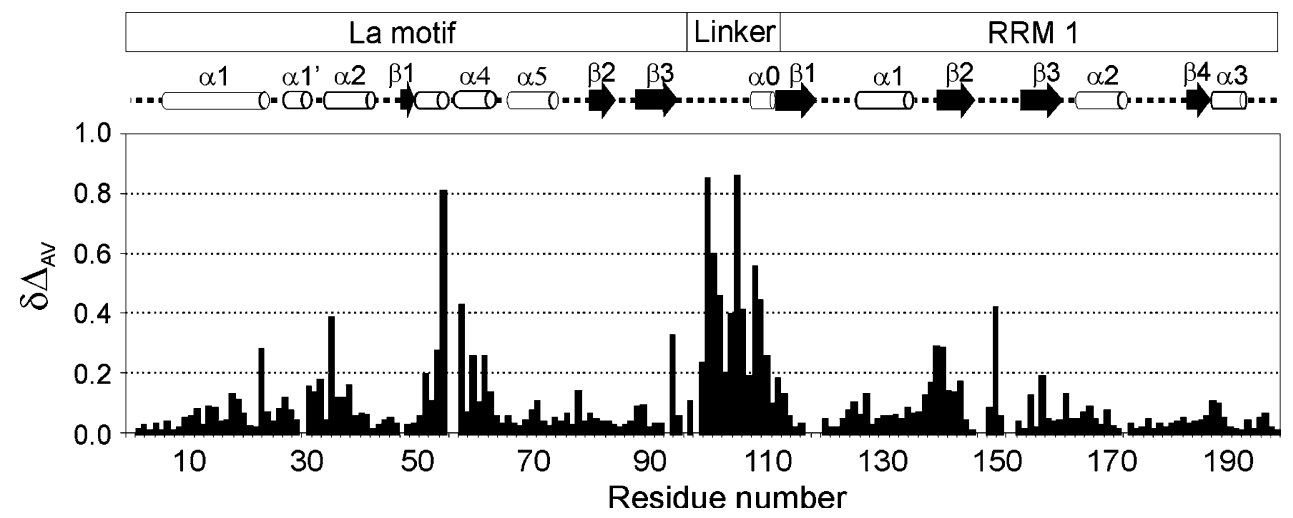

Fig. 2 Chemical shift perturbations of La NTD upon 5'-UUUU RNA interaction. The weighted average of ${ }^{15} \mathrm{~N}$ and ${ }^{1} \mathrm{H}_{\mathrm{N}}$ chemical shift variation $\Delta \delta_{\mathrm{AV}}=\left\{0.5\left[\Delta \delta\left({ }^{1} \mathrm{H}_{\mathrm{N}}\right)^{2}+\left(0.2 \Delta \delta\left({ }^{15} \mathrm{~N}\right)\right)^{2}\right]\right\}^{1 / 2}$ is reported as function of the protein sequence. The cartoon representation of the secondary structure delineation is reported for the apo La NTD form. The strong chemical shift variation observed in the linker region corresponds to the formation of an $\alpha$-helix (see text) 
In the free protein the backbone and side chains chemical shifts of the individual La (Sanfelice et al. 2004) and RRM domains (Alfano et al. 2003) (accession numbers 6044 and 5719 , respectively) remained virtually unchanged in the longer NTD fragment, in agreement with the finding that in absence of RNA the two domains behave independently in solution (Kotik-Kogan et al. 2008). For the interdomain linker (residues 102-107) only the assignment of backbone residues could be obtained, since the severe line broadening and spectral overlap prevented a more extensive assignment to be achieved. Backbone and ${ }^{13} \mathrm{C} \beta$ assignment for apo La NTD used for secondary structure and relaxation analysis reported in Kotik-Kogan et al. (2008) have been deposited in the BioMagResBank database, accession number 15726 .

Conversely, numerous backbone and side chains resonances of La NTD experienced chemical shifts changes upon interaction with $5^{\prime}$-UUUU (Fig. 2). In this complex, the $\mathrm{H}_{\mathrm{N}}$, $\mathrm{N}, \mathrm{C}^{\prime}, \mathrm{C} \alpha, \mathrm{C} \beta$ and $\mathrm{H} \alpha$ assignments were performed at $\sim 92 \%$ completeness, and for the side chains $\sim 77 \%$ of the ${ }^{1} \mathrm{H}$ and ${ }^{13} \mathrm{C}$ resonances were unambiguously identified. A number of protein signals suffered severe spectral broadening in the complex, and these correspond mainly to side chains at the interface with the RNA ligand (Kotik-Kogan et al. 2008), which thus could not be assigned. Interestingly, the interdomain linker peaks became sharper and better resolved compared to the apo protein, and in the complex an almost complete assignment of side chain resonances in this stretch could be attained. This is indicative of a stabilisation in this region, in agreement with chemical shifts analysis, TALOSreported $\phi$ and $\varphi$ backbone dihedral angles and NOE data, which revealed an increase in the degree of helical structure for the interdomain linker (Kotik-Kogan et al. 2008). This conformational rearrangement was confirmed by crystallographic data of La NTD in complex with several 3 '-uridylate RNA targets (Kotik-Kogan et al. 2008). The chemical shifts for the 5'UUUU-bound La NTD have been deposited in the BioMagResBank database, accession number 15727.
Acknowledgements This work was supported by grant funding from Wellcome Trust to MRC and SC. We are grateful to Drs J. Keene, D. Kenan and N. Sonenberg for the gift of human La cDNA. We also thank Dr. Andrew Beavil for help with the computer network.

Open Access This article is distributed under the terms of the Creative Commons Attribution Noncommercial License which permits any noncommercial use, distribution, and reproduction in any medium, provided the original author(s) and source are credited.

\section{References}

Alfano C, Babon J, Kelly G, Curry S, Conte MR (2003) Resonance assignment and secondary structure of an $\mathrm{N}$-terminal fragment of the human La protein. J Biomol NMR 27:93-94

Alfano C, Sanfelice D, Babon J, Kelly G, Jacks A, Curry S, Conte MR (2004) Structural analysis of cooperative RNA binding by the La motif and central RRM domain of human La protein. Nat Struct Mol Biol 11:323-329

Bartels C, Xia T, Billeter M, Güntert P, Wüthrich K (1995) The program XEASY for computer supported NMR spectral-analysis of biological macromolecules. J Biomol NMR 6:1-10

Curry S, Conte MR (2006) A terminal affair: $3^{\prime}$-end recognition by the human La protein. Trends Biochem Sci 31:303-305

Delaglio F, Grzesiek S, Vuister GW, Zhu G, Pfeifer J, Bax A (1995) NMRPipe: a multidimensional spectral processing system based on UNIX pipes. J Biomol NMR 6:277-293

Johnson BA, Blevins RA (1994) NMRVIEW: a computer program for the visualization and analysis of NMR data. J Biomol NMR 4:603-614

Kotik-Kogan O, Valentine E, Sanfelice D, Conte MR, Curry S (2008) Structural analysis reveals conformational plasticity in the recognition of RNA $3^{\prime}$-ends by the human La protein. Structure. doi:10.1016/j.str.2008.02.021

Sanfelice D, Babon J, Kelly G, Curry S, Conte MR (2004) Resonance assignment and secondary structure of the La motif. J Biomol NMR 29:449-450

Teplova M, Yuan YR, Phan AT, Malinina L, Ilin S, Teplov A, Patel DJ (2006) Structural basis for recognition and sequestration of $\mathrm{UUU}(\mathrm{OH}) 3^{\prime}$-temini of nascent RNA polymerase III transcripts by La, a rheumatic disease autoantigen. Mol Cell 21:75-85

Wolin SL, Cedervall T (2002) The La protein. Annu Rev Biochem 71:375-403 